\title{
Homeobox A11 hypermethylation indicates unfavorable prognosis in breast cancer
}

\author{
Bingshu Xia ${ }^{1}$, Ming Shan ${ }^{1}$, Ji Wang ${ }^{1}$, Zhenbin Zhong ${ }^{1}$, Jingshu Geng ${ }^{2}$, Xiaohui He ${ }^{3}$, \\ Tung Vu ${ }^{4}$, Dekai Zhang ${ }^{4}$, Da Pang ${ }^{1,5}$ \\ ${ }^{1}$ Department of Breast Surgery, Harbin Medical University Cancer Hospital, Harbin, 150081, China \\ ${ }^{2}$ Department of Pathology, Harbin Medical University Cancer Hospital, Harbin, 150081, China \\ ${ }^{3}$ Department of Medical Records, Harbin Medical University Cancer Hospital, Harbin, 150081, China \\ ${ }^{4}$ Center for Infectious and Inflammatory Diseases, Institute of Biosciences and Technology, Texas A\&M University Health \\ Science Center, Houston, Texas, 77030, USA \\ ${ }^{5}$ Heilongjiang Academy of Medical Sciences, Heilongjiang Province, Harbin, 150086, China \\ Correspondence to: Da Pang, email: pangda@ems.hrbmu.edu.cn \\ Dekai Zhang, email: dzhang@ibt.tamhsc.edu
}

Keywords: breast cancer, DNA methylation, HOX genes, biomarker, prognosis

Received: April 12, $2016 \quad$ Accepted: December 05, 2016

Published: December 25, 2016

\section{ABSTRACT}

Homeobox A11 (HOXA11) is one of the hypermethylated genes in breast cancer and its function in breast tumorigenesis remains elusive. In this study, we analyzed the methylation status of HOXA11 in 264 paired breast cancer and normal tissue as well as in matched serum samples by MethyLight assay. Further, the function of HOXA11 in breast tumorigenesis was analyzed by cell proliferation and migration assays. We found that HOXA11 was hypermethylated in cancer tissues $(45.08 \%)$, especially in invasive ductal carcinomas $(P<0.001)$, patients with a family history of cancer $(P=0.033)$, cases with metastatic lymph nodes $(P=0.004)$ and $P 53$ positive group $(P=0.017)$. Kaplan-Meier survival analysis and Cox regression analysis revealed that HOXA11 hypermethylation is an independent predictor of poor outcomes. The over expression of HOXA11 suppressed cell growth in MDA-MB-231, MCF7, SKBR3 and BT474 cells. In conclusion, the hypermethylation of HOXA11 is an independent prognostic biomarker in breast cancer. Additionally, HOXA11 can be a potential tumor suppressor.

\section{INTRODUCTION}

Aberrant methylation of normally unmethylated $\mathrm{CpG}$ islands in promoter region has been associated with transcriptional inactivation of tumor suppressor genes which frequently undergo LOH in human cancers [1]. Attenuation of tumor suppressor genes by promoter methylation is implicated in tumorigenicity. These findings encourage us to identify potential tumor suppressor genes by screening methylation status of $\mathrm{LOH}$ loci including chromosome 7 [2]. One of the top ranked genes is HOXA11.

HOX proteins function as transcriptional factors through homeodomain, a highly conserved DNA binding domain, and are deregulated in cancers [3] including breast cancer $[4,5]$. HOXA11, as a member of HOX proteins, locates in the cluster with other contiguous HOXA genes along the short arm of chromosome 7 [6] (Supplementary Figure 1). Recently, hypermethylation of HOXA11 is uncovered in ovarian cancer [7], lung cancer [8], gastric cancer [9] and breast cancer [10, 11]. Despite the methylation patterns in cancer, the clinical significance of HOXA11 methylation and its function in breast cancer remains elusive.

In this study, we used MethyLight assay to evaluate the methylation level of HOXA11 promoter region in paired normal and cancer tissues as well as in matched serum samples, then determined whether methylation status is associated with clinicopathological features or disease prognosis. We additionally analyzed the correlation between HOXA11 methylation and its function in cell proliferation and migration.

\section{RESULTS}

Methylation profile of HOXA11 in breast cancer

264 paired cancer and normal tissues collected after potential curative resections of breast cancers were 
examined by MethyLight assay using HOXA11 promoter region specific primers and probe (Supplementary Figure 1). Hypermethylation of HOXA11 represented 119 out of $264(45.08 \%)$ primary breast tumors surveyed, while only $6.82 \%$ of normal tissues were defined as HOXA11 hypermethylation. The methylation rate $(16.36 \%)$ of HOXA11 in matched serum samples was much lower than in tumors (Figure 1A).

\section{HOXA11 hypermethylation is a prognostic biomarker in breast cancer}

We wondered whether the methylation level of HOXA11 promoter has any correlation with clinicopathological characteristics (Table 1). When comparing HOXA11 methylation level to clinical features, we noticed a significant higher incidence of hypermethylation in invasive ductal carcinomas (IDCs), patients with a family history of cancer, cases with metastatic lymph nodes and P53 positive group than their counterparts. There was no statistically significant correlation between HOXA11 methylation and other clinical pathological factors, including age, tumor size, stage, histological grade, ER status, PR status, HER2 status, Ki67 status and molecular subtypes.

Next, we investigated the relationship between overall survival and HOXA11 methylation. Kaplan-Meier survival analysis revealed that HOXA11 hypermethylation is a significant predictor of subsequently death $(\mathrm{P}=0.0002$, Figure 1B). Both univariate (Supplementary Table 1) and multivariate (Table 2) analyses were applied to evaluate the effects of HOXA11 methylation and clinicopathological features on prognosis. In Cox proportional hazards model, HOXA11 methylation $(\mathrm{P}<0.001)$, tumor size $(\mathrm{P}=0.005)$ and histological grade
$(\mathrm{P}=0.002)$ were significant independent predictors of poorer clinical outcome. Therefore, HOXA11 methylation is an independent prognostic factor in breast cancer.

\section{Demethylation restored HOXA11 mRNA expression in breast cancer cell lines}

We employed methylation specific PCR (MSP) to determine the methylation status of HOXA11 in breast cancer cell lines. Two sets of primers targeting the $\mathrm{CpG}$ island near the transcription start site in the promoter region of HOXA11 [12] were employed to evaluate the methylation status in naive MCF-7 and MDA-MB-231 cells (Figure 2A). The promoter region was completely methylated in MDAMB-231 cells and partially methylated in MCF-7 cells. Later, MCF-7 and MDA-MB-231 cells were treated with 5-aza-2'-deoxycytidine, a pharmaceutical demethylation reagent (Figure 2A). The demethylation restored the expression of HOXA11 in MDA-MB-231 $(\mathrm{P}=0.0215)$ and MCF-7 cells $(\mathrm{P}=0.0013)$ (Figure $2 \mathrm{~B})$. These results indicated that HOXA11 methylation correlated inversely with its expression in MDA-MB-231 and MCF-7 cells.

\section{High expression of HOXA11 inhibits cell proliferation}

To investigate the function of HOXA11 in carcinogenesis, cell proliferation and migration were analyzed in MDA-MB-231, MCF-7, SKBR3 and BT474 cells. We tested the protein level in breast cancer cell lines and clinical samples (Supplementary Figure 2). Transient over expression of HOXA11, validated by qPCR (data not shown), suppressed cell proliferation in all four cell lines (Figure 3A) and slightly delayed wound closure in MDAMB-231 cells (Figure 3B, $P=0.1341$ ). Unfortunately,
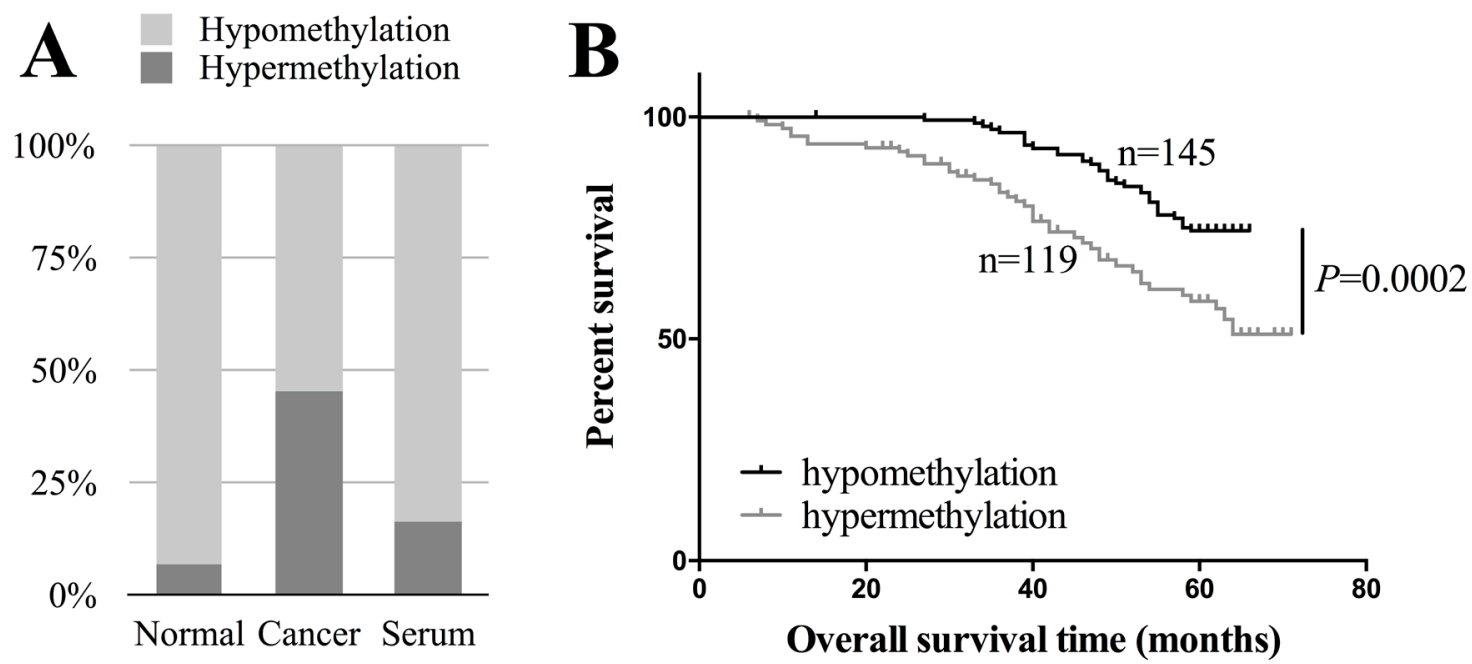

Figure 1: Identification of HOXA11 as a hypermethylated gene in breast cancer. A. The methylation rates in breast cancer tissues, paired normal tissues and matched serum samples were $45.08 \%, 6.82 \%$ and $16.36 \%$, respectively. B. Kaplan-Meier curves show that patients with hypermethylated HOXA11 have a significant worse prognosis than with hypomethylation of HOXA11 (P=0.0002, logrank test). The cut-off value is 1.5 in MethyLight assay. 
Table 1: The correlation between HOXA11 promoter methylation and clinicopathological parameters

\begin{tabular}{|c|c|c|c|c|}
\hline \multicolumn{2}{|c|}{ Characteristics } & \multirow{2}{*}{$\begin{array}{c}\text { hypomethylation } \\
89(53.0 \%)\end{array}$} & \multirow{2}{*}{$\begin{array}{c}\text { hypermethylation } \\
79(47.0 \%)\end{array}$} & \multirow{2}{*}{$\frac{P \text { value }}{0.399}$} \\
\hline Age & $<50 y$ & & & \\
\hline & $\geq 50 y$ & $56(58.3 \%)$ & $40(41.7 \%)$ & \\
\hline \multirow[t]{2}{*}{ Family history } & no & $134(57.3 \%)$ & $100(42.7 \%)$ & 0.033 \\
\hline & yes & $11(36.7 \%)$ & $19(63.3 \%)$ & \\
\hline \multirow[t]{2}{*}{ Pathology } & DCIS & $25(96.2 \%)$ & $1(3.8 \%)$ & $<0.001$ \\
\hline & IDC & $120(50.4 \%)$ & $118(49.6 \%)$ & \\
\hline \multirow[t]{2}{*}{ Tumour size } & $\leq 2 \mathrm{~cm}$ & $66(52.0 \%)$ & $61(48.0 \%)$ & 0.354 \\
\hline & $>2 \mathrm{~cm}$ & $79(57.7 \%)$ & $58(22.0 \%)$ & \\
\hline \multirow[t]{2}{*}{ LNM } & negative & $72(65.5 \%)$ & $38(34.5 \%)$ & 0.004 \\
\hline & positive & $63(43.8 \%)$ & $81(56.3 \%)$ & \\
\hline \multirow[t]{2}{*}{ TNM Stage } & $0, \mathrm{I}$ & $38(50.0 \%)$ & $38(50.0 \%)$ & 0.306 \\
\hline & II, III & $107(56.9 \%)$ & $81(43.1 \%)$ & \\
\hline \multirow[t]{2}{*}{ Histological Grade } & I, II & $106(55.2 \%)$ & $86(44.8 \%)$ & 0.89 \\
\hline & III & $39(54.2 \%)$ & $33(45.8 \%)$ & \\
\hline \multirow[t]{2}{*}{ ER status } & negative & $57(61.3 \%)$ & $36(38.7 \%)$ & 0.126 \\
\hline & positive & $88(51.5 \%)$ & $83(48.5 \%)$ & \\
\hline \multirow[t]{2}{*}{ PR status } & negative & $62(57.4 \%)$ & $46(42.6 \%)$ & 0.502 \\
\hline & positive & $83(53.2 \%)$ & $73(46.8 \%)$ & \\
\hline \multirow[t]{2}{*}{ HER2 status } & negative & $88(53.3 \%)$ & $77(46.7 \%)$ & 0.504 \\
\hline & positive & $57(57.6 \%)$ & $42(42.4 \%)$ & \\
\hline \multirow[t]{2}{*}{ Ki67 status } & negative & $95(57.2 \%)$ & $71(42.8 \%)$ & 0.329 \\
\hline & positive & $50(51.0 \%)$ & $48(49.0 \%)$ & \\
\hline \multirow[t]{2}{*}{ P53 status } & negative & $113(59.5 \%)$ & $77(40.5 \%)$ & 0.017 \\
\hline & positive & $32(43.2 \%)$ & $42(56.8 \%)$ & \\
\hline \multirow[t]{4}{*}{ Molecular Subtypes } & Luminal A & $76(53.1 \%)$ & $67(46.9 \%)$ & 0.799 \\
\hline & Luminal B & $25(53.2 \%)$ & $22(46.8 \%)$ & \\
\hline & HER2 & $27(61.4 \%)$ & $17(38.6 \%)$ & \\
\hline & TNBC & $17(56.7 \%)$ & $13(43.3 \%)$ & \\
\hline
\end{tabular}

Abbreviations: DCIS = ductal carcinoma in situ; ER = estrogen receptor; IDC = invasive ductal carcinoma; LNM = lymph node metastasis; $\mathrm{PR}=$ progesterone receptor; $\mathrm{TNBC}=$ triple negative breast cancer; $\mathrm{TNM}=$ tumor node metastasis.

no statistically significance was found in cell migration analyses in all four cell lines. Thus, HOXA11 suppressed cell proliferation but not cell migration in breast cancer cells.

\section{Low expression of HOXA11 is associated with poor prognosis}

DNA methylation is a key mechanism in gene silencing. We evaluated the mRNA expression level of
HOXA11 in another 30 pairs of breast cancer and normal tissues which were randomly chosen from the hospital's biobank. The average expression level of HOXA11 in cancer tissues was significantly lower than in normal tissues (Figure 4A). Since we did not have HOXA11 expression data of the cohort employed in methylation analyses, we accessed TCGA database to investigate the correlation between HOXA11 mRNA expression and overall survival. As we expected, the survival probability of HOXA11 high expression group was markedly higher 
Table 2: Prognostic factors in the Cox proportional hazards model

\begin{tabular}{lcc}
\hline \multirow{2}{*}{ Variables } & \multicolumn{2}{c}{ Multivariate } \\
\cline { 2 - 3 } Age (years) & P value & $\mathbf{9 5 \%}$ CI \\
Tumor size (cm) & 0.724 & $0.571-1.475$ \\
LNM & 0.005 & $0.282-0.794$ \\
TNM Stage & 0.104 & $0.332-1.109$ \\
Histological grade & 0.238 & $0.430-1.233$ \\
HER2 status & 0.002 & $1.626-9.154$ \\
HOXA11 methylation & 0.912 & $0.625-1.693$ \\
\hline
\end{tabular}

Abbreviations: $\mathrm{CI}=$ confidence interval; $\mathrm{ER}=$ oestrogen receptor; $\mathrm{LNM}=$ lymph node metastasis; $\mathrm{PR}=$ progesterone receptor; TNM = tumour node metastasis.

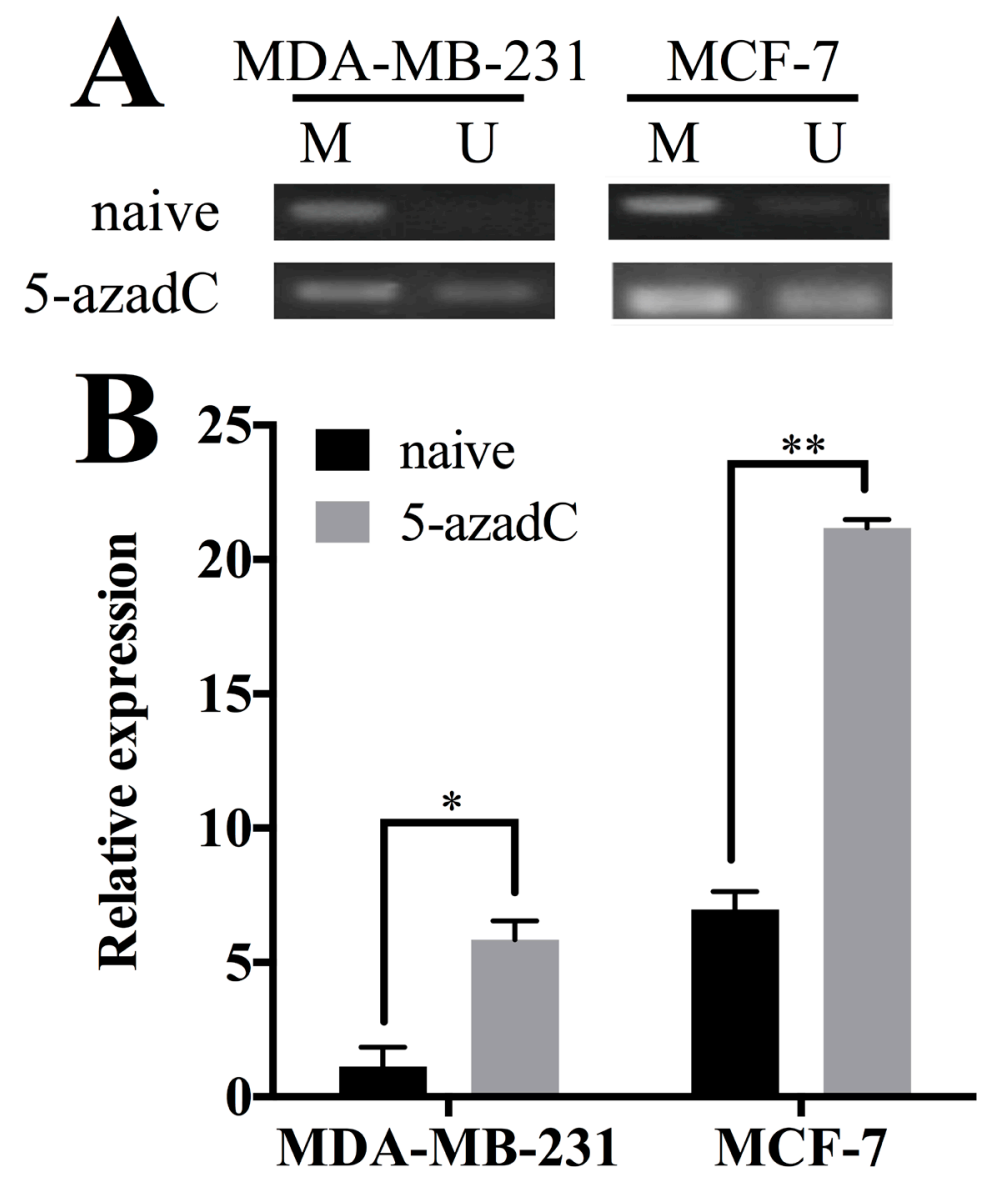

Figure 2: Hypermethylation of HOXA11 controls its expression in breast cancer. A. The methylation levels of HOXA11 promoter region in MDA-MB-231 and MCF-7 cells with or without 5-azadC treatment. The methylated control was genomic DNA methylated by M.SssI and the unmethylated control was peripheral lymphocyte DNA. B. 5-azadC treatment restored HOXA11 expression in MDA-MB-231 ( $\mathrm{P}=0.0215)$ and MCF-7 cells $(\mathrm{P}=0.0013)$. Black columns represent the expression level in cells without treatment. Gray columns represent the expression level in cells with 5-azadC treatment. Values are means $\pm \mathrm{SD}$, and the mean values obtained with naive MDA-MB-231 cells were set to 1 . SD, standard deviation. 
than of HOXA11 low expression group (Figure 4B, $P=0.0425$ ), indicating that low expression of HOXA11 is associated with poor prognosis.

\section{DISCUSSION}

HOXA11, as a member of HOX family, is essential in development [13] and is required in endometrial receptivity and implantation $[14,15]$. Abnormal HOXA11 methylation has been implicated in breast cancer [16-18]. However, the influence of HOXA11 hypermethylation on tumorigenesis is not clear.

In this study, we evaluated HOXA11 methylation level in paired breast cancer and normal tissues as well as in matched serum samples collected from 264 Chinese breast cancer patients. The methylation rate of

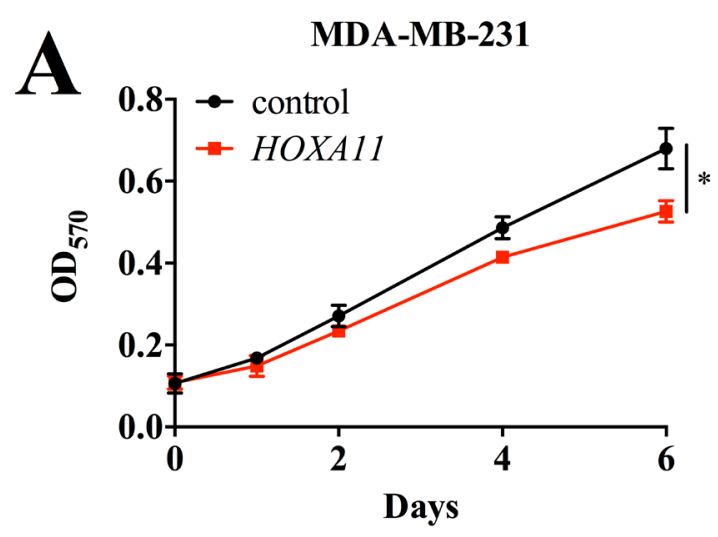

SKBR3

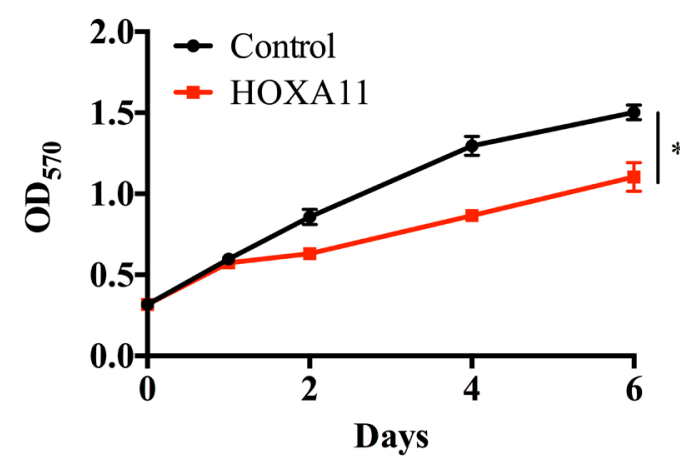

MCF-7
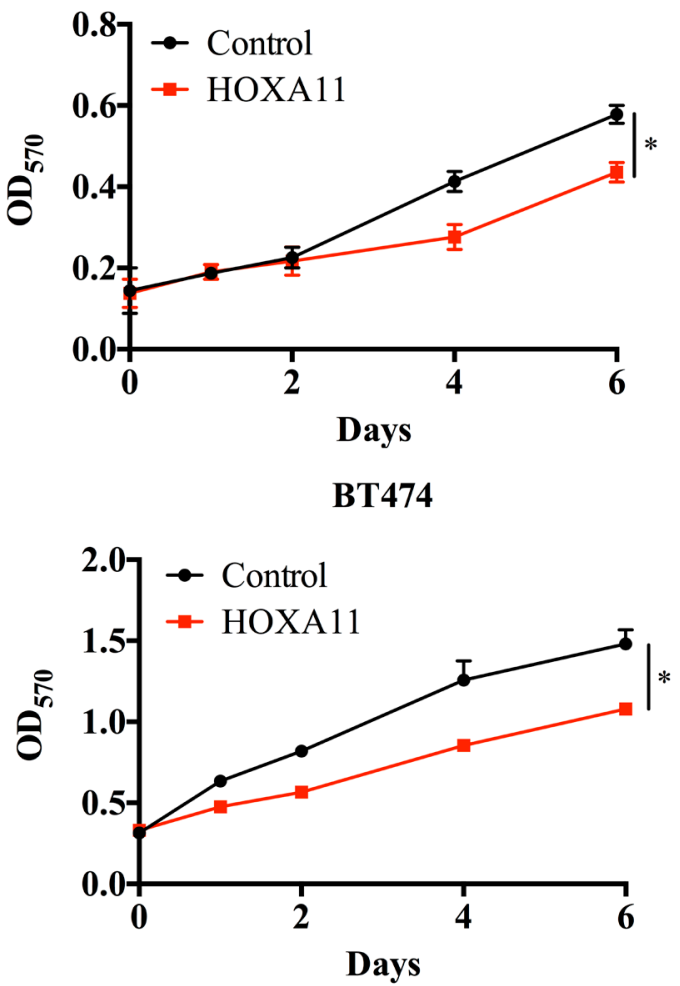

B

$0 \mathrm{~h}$

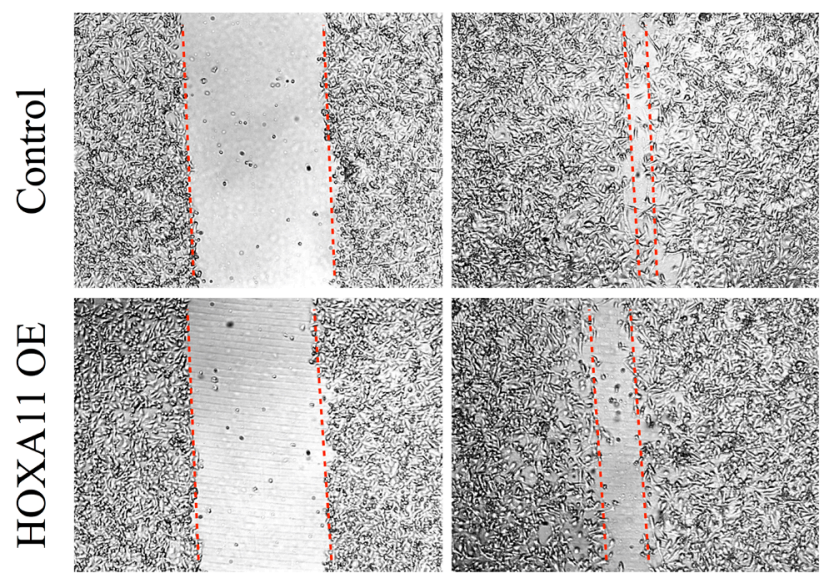

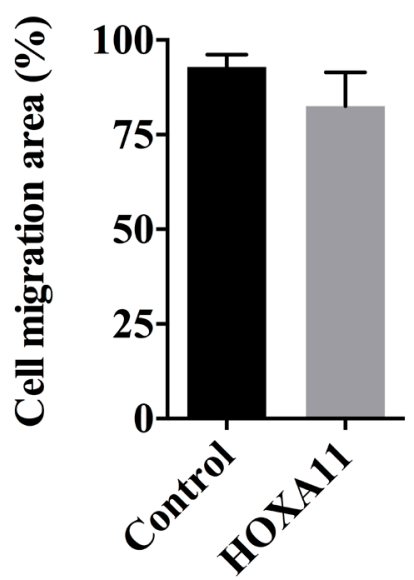

Figure 3: HOXA11 suppressed cell proliferation and migration in MDA-MB-231 cells. A. The over expression of HOXA11 inhibits cell proliferation in MDA-MB-231 ( $\mathrm{P}=0.0322)$, MCF7 ( $\mathrm{P}=0.0493)$, SKBR3 $(\mathrm{P}=0.0409)$ and $\mathrm{BT} 474(\mathrm{P}=0.0320)$ cells. B. Wound healing assay shows that the over expression of HOXA11 inhibits migration in MDA-MB-231 cells. The cell migration area was measured by ImageJ $(\mathrm{P}=0.1341)$. 
HOXA11 is significant higher in cancer tissue (45.08\%) than in paired normal tissue $(6.82 \%)$ and matched serum specimens (16.36\%). Circulating cfDNA released from cancerous tissues into blood reflects the methylation profiles in tumor cells and can be employed as a diagnostic biomarker in breast cancer [19]. The methylation rate of HOXA11 in serum is lower than in matched cancer tissues. According to this result, the alternative causes include cfDNA fragmentation and methods with impaired sensitivity. Although HOXA11 methylation solely is under quantified as a biomarker in serum, it can be combined with other hypermethylated genes to sever as biomarkers to distinguish cancer and normal tissues in non-invasive examination.

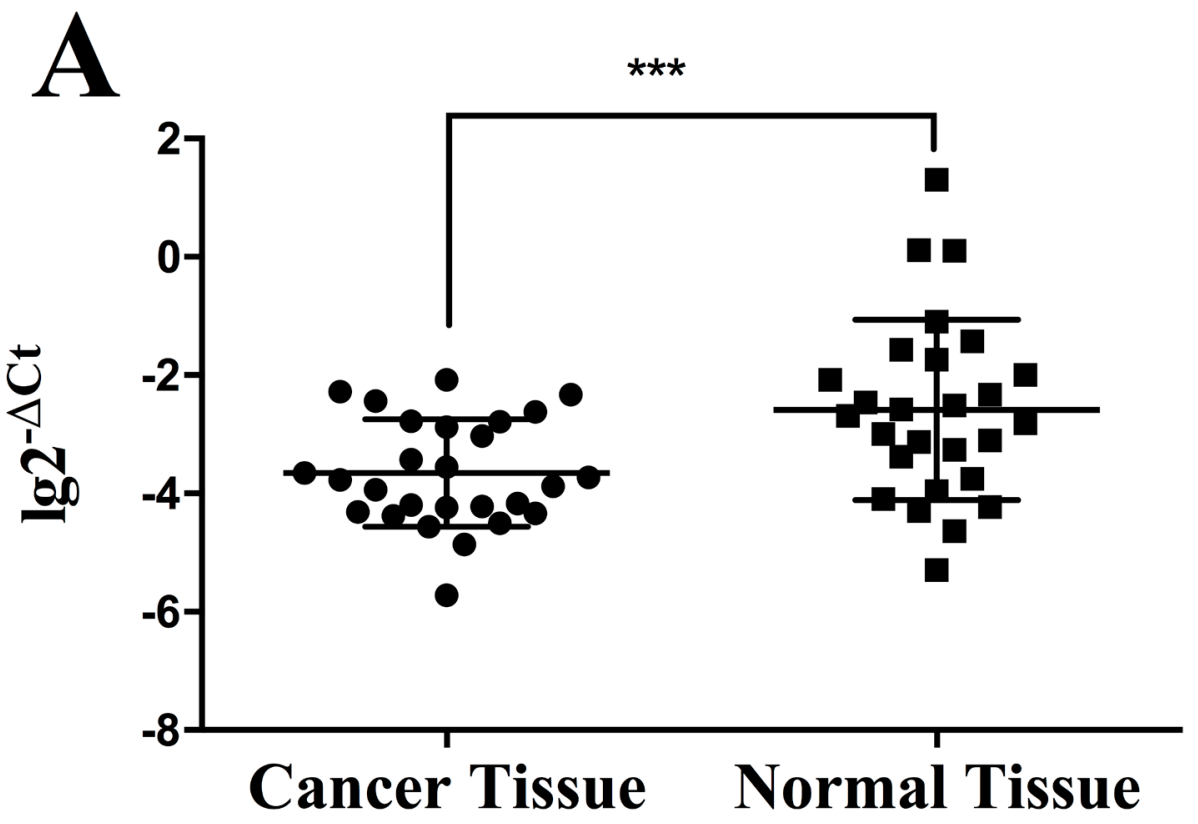

B

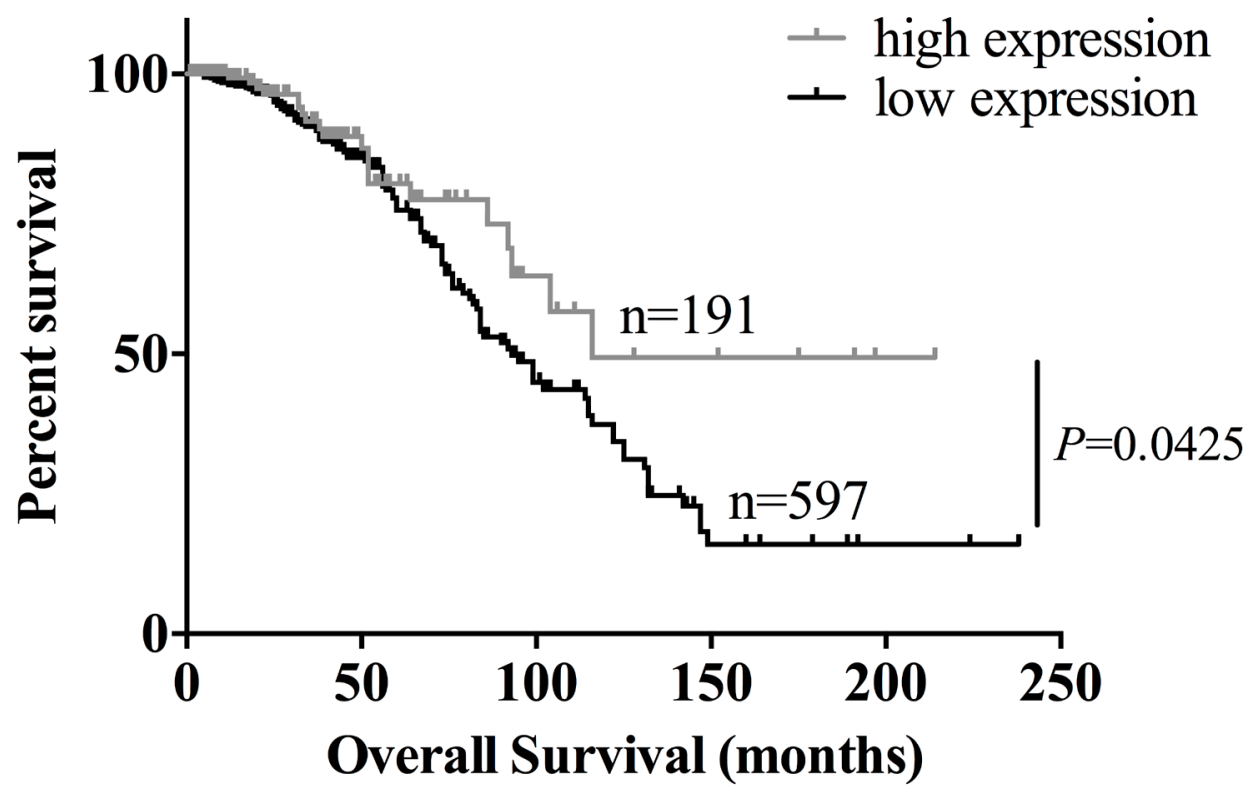

Figure 4: The high expression of HOXA11 prolongs overall survival in breast cancer patients. A. The expression level of HOXA11 in 30 pairs of cancer and normal tissue. The average expression of HOXA11 is lower in cancer tissue than in normal tissue $(\mathrm{P}=0.0007)$. B. Kaplan-Meier curves show that patients with high expression of HOXA11 had a significantly worse prognosis than those with low expression of HOXA11 ( $\mathrm{P}=0.0425$, log-rank test). 
We noticed statistically significant correlations between HOXA11 hypermethylation and positive family history, IDC, positive lymph node metastasis and positive P53 staining (Table 1). First, 30 out of 264 cases have a documented family cancer history and 19 out of these 30 cases were defined as HOXA11 hypermethylated. Additionally, among patients with family cancer histories, the cases with hypomethylation of HOXA11 survived longer than those with hypermethylation (Supplementary Figure 3). The heritability of DNA methylation [20] might be the underlying link between HOXA11 hypermethylation and positive family history. Second, 1 out of 26 ductal carcinoma in situ (DCIS) cases has hypermethylatoin of HOXA11 meanwhile 118 out of 238 IDC cases show a high level of methylation. Considering the dynamics of HOXA11 methylation in development, this result infers the potential role of HOXA11 in breast cancer initiation and promotion. Third, HOXA11 prefers to be hypermethylated in cases with lymph node metastasis. This is consistent with the reports of other cancers [21, 22] and indicates a potential role of HOXA11 in metastasis. Last, the hypermethylation of HOXA11 is more frequently detected in P53 positive group. Another study of methylation patterns in breast tumors finds out that HOXA11 is highly methylated in P53 wild type groups [18]. The relationship between IHC expression of P53 and the mutational status of the TP53 gene is equivocal [23]. Different cohorts and methods make these two results incomparable. Further studies might be required in understanding the connection between P53 and HOXA11.

The hypermethylation of HOXA11 is an unfavorable prognostic biomarker in several cancers, especially in the female hormone dependent cancers such as ovarian cancer [7] and endometrial adenocarcinoma [21]. Besides, HOXA11 hypermethylation is also an independent predictor in breast cancer (Figure 1B), Table 2. By accessing the TCGA breast cancer database, we discovered that patients with HOXA11 low expression have short overall survival time (Figure 4B). Although it would be more convinced if we had the data of methylation status and expression level of HOXA11 from the same cohort, our results validate the clinical utility of HOXA11 as a biomarker in breast cancer.

HOXA11 expression was restored by 5 -azadC, a demethylation reagent, in breast cancer cell lines in our experiment as well as in previous study [10]. In addition, this phenomenon was also described in other malignancies $[8,22]$. Hence, DNA methylation alone is sufficient to silence HOXA11 in tumors. This universal demethylation reagent re-expresses numbers of genes including HOXA11 and enhances chemosensitivity in breast cancer [24]. We propose that HOXA11 might be a potential therapeutic target. In order to investigate the function of HOXA11 in breast cancer, we employed cell proliferation assay and observed an inhibition effect in all analyzed cell lines (Figure 3A). The similar response has been discovered in non-small cell lung cancer [8] and gastric cancer [22].
Based on previous studies and our results, HOXA11 is a potential tumor suppressor in breast cancer.

However, the underlying mechanism of HOXA11's anti-tumor activity is unclear. Previous study shows that HOXA11 might inhibit gastric cancer through Wnt signaling pathway [22]. Moreover, non-coding RNAs were deemed to exert negatively regulation in HOXA11 expression $[15,25]$. To find out the genes related to HOXA11, we performed PCR microarray assay. The personalized PCR microarray contains a panel of genes related to breast cancer tumorigenesis and development. MDA-MB-231 cells were employed in this assay due to the inhibition of proliferation and migration by HOXA11 overexpression. All genes except ZNF703 and SNAI1 in the microarray panel were upregulated after HOXA11 plasmid transfection (Supplementary Figure 4). ZNF703 was identified as the driver of $8 \mathrm{p} 12$ locus amplication in breast cancer development [26]. Snail encoded by SNAI1 plays a role in recurrence of breast cancer by downregulating E-cadherin and inducing an epithelial to mesenchymal transition [27]. Thus, the down regulation of ZNF703 and SNAI1 by HOXA11 overexpression may contribute to breast cancer suppression. Further studies are warranted to discern the role of HOXA11 in breast cancer.

In conclusion, the highly methylation of HOXA11 is associated with invasive ductal carcinomas, cases with positive family cancer history, patients with lymph nodes metastasis and P53 positive cases. Hypermethylation of HOXA11 and low expression of HOXA11 also indicate poor prognosis. HOXA11 methylation correlates inversely with its expression. Over expression of HOXA11 inhibits cell proliferation in four breast cancer cell lines. Our finding suggests that HOXA11 can be applied as a clinical biomarker of prognosis and is a potential tumor suppressor in breast cancer.

\section{MATERIALS AND METHODS}

\section{Subjects and sample collection}

Cases for this study came from histologically confirmed breast cancers initially diagnosed between 2009 and 2011 at the Harbin Medical University Cancer Hospital. A total of 264 female breast cancer patients with ages ranging from 21 to 77 years (47.3 years on average) were enrolled in this research and none of them received anti-tumor therapies prior to surgery. A median 60-month follow-up was conducted to all patients, from whom informed consent was obtained. The study complied with the approval institutional guidelines (the Ethical Committee of the Harbin Medical University). The pathological tumor staging was assigned according to the American Joint Committee on Cancer Tumor-NodeMetastasis Classification. Complete clinical and follow-up information was available for all patients.

All specimens $\left(\sim 0.125 \mathrm{~mm}^{3}\right)$ including breast cancer tissues and paired normal tissues (at least 30 
$\mathrm{mm}$ from malignant lesions) were snap-frozen in $-80^{\circ} \mathrm{C}$ freezer within one hour after mastectomy. Matched blood samples were obtained from 264 patients before surgery. Serum was separated by centrifugation within 2 hours after collection and stored at $-80^{\circ} \mathrm{C}$ until use. DNA was extracted from all samples including serum, and was used in a MethyLight assay.

\section{Molecular subtype classification of breast cancer}

All tissue sections of breast cancer specimens were routinely processed in immunohistochemistry (IHC) assays for detection of estrogen receptor (ER), progesterone receptor (PR), human epidermal growth factor receptors 2 (HER2), Ki-67 and P53. Fluorescent in situ hybridization (FISH) was employed only if HER2 amplification was inconclusive in IHC staining. ER and PR staining scores were considered positive if there are at least $1 \%$ positive tumor nuclei in the sample [28]. The standard of HER2 positive was based on the percentage of the membrane staining of tumor cells and the value of a FISH ratio. A positive HER2 result is IHC staining of 3+ or a FISH ratio of more than 2.2 [29]. Cells stained for Ki67 and P53 were counted and represented as a percentage. Low expression was considered as a Ki-67 index of lower than 14\% [30] and P53 of not higher than 25\% [31].

Molecular subtypes of breast cancer were classified according to the criteria approved by The 12th St Gallen International Breast Cancer Conference (2011) Expert Panel [32]. The detailed criteria were as follows: Luminal A type, ER- and/or PR-positive and HER2-negative and low Ki-67 index $(<14 \%$ ); Luminal B type, (HER2negative) ER- and/or PR-positive and HER2-negative and high Ki-67 index ( $\geq 14 \%$ ); (HER2-positive) ER- and/or PR-positive and HER2 over-expressed or amplified and any Ki67 index; HER2-positive type, ER- and PR-negative and HER2 over-expressed or amplified; Triple-negative breast cancer (TNBC) type, ER-, PR- and HER2-negative.

\section{Cell culture}

MDA-MB-231 and MCF-7 cells were cultured in $37^{\circ} \mathrm{C}$ incubator with $5 \% \mathrm{CO}_{2}$ and maintained in DMEM (Lonza, Walkersville, MD, USA) containing 5\% fetal bovine serum (ATCC, Rockville, MD, USA), $100 \mathrm{IU} / \mathrm{ml}$ of penicillin and $100 \mu \mathrm{g} / \mathrm{ml}$ streptomycin (ATCC, Rockville, MD, USA). SKBR3 and BT474 cells were cultured in $37^{\circ} \mathrm{C}$ incubator with $5 \% \mathrm{CO} 2$ and maintained in RPMI (Lonza, Walkersville, MD, USA) containing 5\% fetal bovine serum (ATCC, Rockville, MD, USA), $100 \mathrm{IU} / \mathrm{ml}$ of penicillin and $100 \mu \mathrm{g} / \mathrm{ml}$ streptomycin (ATCC, Rockville, MD, USA).

\section{DNA extraction and bisulfite modification}

Genomic DNA (gDNA) was isolated from 264 pairs of primary breast tumors and corresponding normal tissues using an AxyPrepTM Multisource Genomic DNA Miniprep Kit (Axygen Scientic, San Francisco, CA, USA) following the manufacturer's instructions. Serum cellfree DNA (cfDNA) was obtained from $1 \mathrm{ml}$ of serum by QIAamp Circulating Nucleic Acid Kit (Qiagen, Hilden, Germany) following the manufacturer's protocol. DNA quantification was determined by a spectrophotometer (Gene Quant Pro, Amersham Biosciences, England). The gDNA of cell lines was extracted by phenolchloroform extraction followed by ethanol precipitation and the concentration was determined by NanoDrop 2000 (Thermo Scientific, Hudson, NH, USA).

For clinical samples, $500 \mathrm{ng}$ of gDNA and $100 \mathrm{ng}$ of cfDNA were applied for bisulfite conversion using the EZ DNA Methylation-Gold kit (Zymo Research, Orange, CA, USA) following the manufacturer's protocol. For cell lines, $1 \mu \mathrm{g}$ of gDNA was diluted in water to a final volume of $50 \mu \mathrm{l}$. To create single-strand DNA, the samples were incubated with $5.5 \mu \mathrm{l}$ of $2 \mathrm{M} \mathrm{NaOH}$ at $37^{\circ} \mathrm{C}$ for 10 minutes, and then at room temperature for another 10 minutes. Freshly prepared $30 \mu \mathrm{l}$ of $10 \mathrm{mM}$ hydroquinone (Sigma-Aldrich, St Louis, MO, USA) and $520 \mu \mathrm{l}$ of $3 \mathrm{M}$ sodium bisulfite (Sigma-Aldrich, St Louis, MO, USA) at $\mathrm{pH} 5.0$ were added to each reaction tubes. After 16 hours of incubation in dark at $50^{\circ} \mathrm{C}$, DNA was desalted by Wizard DNA clean-up system (Promega, Madison, WI, USA) and reconstituted in $50 \mu \mathrm{l}$ of distilled water. Then the samples were incubated with $5.5 \mu \mathrm{l}$ of $3 \mathrm{M} \mathrm{NaOH}$ for 5 minutes at room temperature to complete the conversion of unmethylated cytosine to uracil. Bisulfite treated DNA was purified and concentrated by ethanol precipitation and stored at $-80^{\circ} \mathrm{C}$ until use.

\section{MethyLight assay}

Clinical gDNA and cfDNA treated with sodium bisulfite were analysed by MethyLight, a fluorescencebased, real-time quantitative PCR (qPCR) assay, as described previously [33]. TaqMan Minor Groove Binder (Applied Biosystems, Foster City, CA, USA) PCR was performed with primers specific for the bisulfite-converted sequence. Globin was used as an internal reference gene. The primers and probe for globin were as follows: forward primer, 5'-AGGTAGAAAAGGAGAATGAAG ATAAA-3'; reverse primer, 5'-CTTTCCACTCTTTTCT CATTCTCTC-3'; product size, 143 bp; probe sequence, 5'-AGGAGGATAAGGAAGAGGGGAAATAGG-3'. The set of primers and probe for HOXA11 was as follows: forward primer: 5'-GTTGTTGGCGGTTTAGGGAC-3'; reverse primer: 5'-GCCTCTACCTCCGACCCTAA-3'; product size is $167 \mathrm{bp}$; probe sequence: 5'-AGAGTGTAATTAAGTTATCGTGTA-3'. For each PCR reaction, $2.5 \mathrm{mM} \mathrm{MgCl}_{2}, 10 \mu \mathrm{M}$ dNTP, $0.25 \mu \mathrm{M}$ forward and reverse primers, $0.1 \mu \mathrm{M}$ probe, $1 \times$ Platinum Taq buffer and 0.5 unit of Platinum Taq polymerase (Invitrogen, Carlsbad, CA, USA) were used in a total 
volume of $10 \mu \mathrm{l}$. PCR was performed under the following conditions: $95^{\circ} \mathrm{C}, 3 \mathrm{~min}$; followed by 45 cycles of $95^{\circ} \mathrm{C}$ for $10 \mathrm{~s}$ and $60^{\circ} \mathrm{C}$ for $30 \mathrm{~s}$. Cycle threshold $(\mathrm{Ct})$ values obtained in PCR analyses were used as a measure of the degree of methylation at the analyzed locus. Relative quantification was performed based on the threshold cycles of HOXA11 and internal reference gene (globin). The value of methylation at a specific locus was calculated by the $2^{-\Delta \Delta \mathrm{Ct}}$ method [34], where $\Delta \Delta \mathrm{Ct}=\left(\mathrm{Ct}_{\text {(HOXA11) }}-\mathrm{Ct}_{\text {(globin) }}\right)_{\text {cancer }}-(\mathrm{Ct}$ (HoXA11) $\left.-\mathrm{Ct}_{\text {(globin) }}\right)_{\text {normal }}$. The cut-off value of $\geq 1.5$ [35] was delineated as hypermethylation in cancer tissue. In normal tissue, the gene of interest was considered unmethylated if its $\mathrm{Ct}$ value was $\geq 40$. The relative methylation level in serum was calculated by the $2^{-\Delta \mathrm{Ct}}$ method, where $\Delta \mathrm{Ct}=\mathrm{Ct}$ (HOXA11) $-\mathrm{Ct}_{\text {(globin) }}$ [36] All amplification efficiencies were similar. We tested each sample in triplicate.

\section{Methylation specific PCR (MSP)}

MSP used to determine the methylation status of HOXA11 promoter region was performed as previously described [37]. MSP amplification was carried out with the following reaction mixture: $10 \mu \mathrm{l}$ of PCR master buffer (GeneDEPOT, Barker, TX, USA), $1 \mu$ of Taq DNA polymerase (GeneDEPOT, Barker, TX, USA), $1 \mu \mathrm{l}$ of 10 $\mu \mathrm{M}$ methylated or unmethylated primers, $50 \mathrm{ng}$ of template DNA and distilled water brought the final volume to 20 $\mu \mathrm{l}$. Genomic DNA methylated by M.SssI (New England Biolabs, Beverly, MA, USA) was used as a methylated control and peripheral lymphocyte DNA modified by sodium bisulfite was used as a unmethylated control. The methylated primers were as follows: forward primer, 5'-GTTTACGGT GTTATAGAAATTGGAC-3'; reverse primer, 5'-GTACAC AAAAACTACCTACAAACGC-3'; product length, 129bp. The unmethylated primers were as follows: forward primer, 5'-TTTATGGTGTTATAGAAATTGGATGA-3'; reverse primer, 5'-TCATACACAAAAACTACCTACAAACAC-3'; product length, 130bp [12]. A total of 35 cycles were run with an annealing temperature of $55^{\circ} \mathrm{C}$. PCR products were visualized after electrophoresis on $2 \%$ agarose (SigmaAldrich, St Louis, MO, USA) gels staining with ethidium bromide (Thermo Scientific, Hudson, NH, USA).

\section{5-aza-2'-deoxycytidine (5-azadC) treatment}

For 5-azadC (TCI America, Portland, OR, USA) treatment, MDA-MB-231 and MCF-7 cells were grown in a 6-well plate at low density and treated with $20 \mu \mathrm{M}$ of 5-azadC dissolved in distilled water for 72 hours [38]. The culture medium with 5-azadC was refreshed every 12 hours. Cells without treatment were used as a control.

\section{HOXA11 mRNA expression}

The total RNA of breast cancer cell lines was extracted with E.Z.N.A. total RNA kit (Omega Bio-tek Inc., Norcross, GA, USA). Reverse transcription (Quanta Biosciences,
Gaithersburg, MD, USA) followed by qPCR (BIOLINE, Taunton, MA, USA) was employed to determine the mRNA expression of HOXA11. QPCR was performed under the following conditions: $95^{\circ} \mathrm{C}, 3 \mathrm{~min}$; followed by 40 cycles of $95^{\circ} \mathrm{C}$ for $30 \mathrm{~s}, 58^{\circ} \mathrm{C}$ for $30 \mathrm{~s}$ and $72^{\circ} \mathrm{C}$ for $30 \mathrm{~s} ; 72^{\circ} \mathrm{C}$ for 7 minutes and $4^{\circ} \mathrm{C}$ hold. The set of primers was as follows: forward primer, 5'-CGGCAGCAGAGGAGAAAG-3'; reverse primer, 5'-TATAGGGGCAGCGCTTTT-3'; product length, $132 \mathrm{bp}$.

\section{Transient transfection}

HOXA11 over expression plasmid shared by Dr. Wagner at Yale [39] was used in transient transfection with FuGENE 6 (Promega, Madison, WI, USA). The expression level of HOXA11 after transfection was determined with qPCR. MTT assay and wound healing assay were performed 24 hours post-transfection.

\section{MTT assay}

MDA-MB-231 cells, MCF-7, SKBR3 and BT474 cells were seeded into 96-well plate at 2,500 cells and 5,000 cells per well, respectively. Transient transfection was performed on day-1 (24 hours prior to MTT assay). To measure cell proliferation, the cells were incubated with MTT reagent (AMRESCO, Solon, OH, USA) for 2 to 4 hours on day 0 , day 1 , day 2 , day 4 and day 6 . The absorbance at 570nm was recorded on the indicated days. Each assay was performed in triplicate.

\section{Wound healing assay}

HOXA11 over expressed group and control group were seeded into 24-well plate and cultured overnight. A scratch wound was created with a sterile $200 \mu \mathrm{l}$ tip in each well when cell confluence reached 100\%. Microscopic photography was taken right after scratching and 48 hours later. The cell migration area was measured with ImageJ (NIH, Bethesda, MD, USA). Each assay was performed in triplicate.

\section{Western blot}

The total protein from frozen tissues and breast cancer cell lines was purified using RIPA Buffer. Per sample, $30 \mathrm{mg}$ of protein was loaded into a denaturing polyacrylamide gel containing SDS and transferred to a metha- nol-activated PVDF filter membrane (BioRad, Hercules, CA, USA). Before immunodetection, membranes were blocked with 5\% non-fat dry milk. Primary antibodies, anti-HOXA11 (1:300; Cat\#ab72591, Abcam, Cambridge, MA, USA) were diluted in the blocking buffer and incubated at 4 overnight. After subsequently washing with TBST, the membranes were incubated with secondary antibody for 2 hours at room temperature. Beta-actin (Cat\#TA-09, ZSGB-Bio) was used 
as internal reference protein. The experiment was repeated in triplicate. The bands were visulized by enhanced chemiluminescence detection reagents (Applygen Technologies Inc., Beijing, China).

\section{PCR microarray}

Total cellular RNA was purified from MDA-MB-231 transfected with HOXA11 overexpression plasmid, harvested at $24 \mathrm{~h}$ and $48 \mathrm{~h}$, and compared on microarray against mock transfected control. cDNA was generated by ReverTra Ace qPCR RT Kit (TOYOBO, Shanghai, China). The customized arrays used in the experiments were manufactured by QIAGEN (CAPH12267, QIAGEN, Valencia, CA, USA). Each sample was performed in triplicate. The data was analyzed by $\mathrm{R}$.

\section{Analyse data in TCGA (The cancer genome atlas) database}

In order to review the association between HOXA11 expression and overall survival, we accessed TCGA breast invasive carcinoma gene expression database (RNAseq, IlluminaHiSeq, V2, Feb 24, 2015) by cancer browser at https://genome-cancer.ucsc.edu/. In model of a binary variables, we interpreted mRNA expression of HOXA11 as high expression if the value is above 4.5 , and as low expression if the value is under 4.5. By these criteria, 191 cases were classified as HOXA11 high expression and 597 cases were defined as HOXA11 low expression.

\section{Statistical analysis}

Statistical analyses were performed by IBM SPSS software 20.0 (IBM Corp., Armonk, NY, USA) and GraphPad Prism 6.0 (GraphPad Software Inc., La Jolla, CA, USA). Chi-square test was used to detect differences in clinical data and Student's t-test was employed for experimental data. Kaplan-Meier survival curves using log-rank statistics was used to evaluate the association of overall survival and the expression or methylation of HOXA11. Cox multivariate regression analyses were performed to evaluate the influence of different variables on survival. Only variables with $\mathrm{P}<0.1$ in the univariate analysis were included in the multivariate model. Risk ratios and their $95 \%$ confidence intervals were recorded for each marker. A P-value less than 0.05 was considered statistically significant for all analyses.

\section{ACKNOWLEDGMENTS}

The authors thank the doctors and patients who participated in this study.

\section{CONFLICTS OF INTEREST}

The authors declare no conflicts of interest.

\section{GRANT SUPPORT}

This project was supported by grants from project of Heilongjiang Province Applied Technology Research and Development (GA13C201), Specific research fund for Public Service Sector, National Health and Family Planning Commission of the People's Republic of China (201402003) and National Key Technology Support Program (2014BAI09B08). This work is also supported in part by National Institutes of Health Grant (CA176698, to D. Z.)

\section{REFERENCES}

1. Ehrlich M. DNA methylation in cancer: too much, but also too little. Oncogene. 2002; 21: 5400-5413.

2. Bièche I, Khodja A, Driouch K, Lidereau R. Genetic alteration mapping on chromosome 7 in primary breast cancer. Clin Cancer Res 1997; 3: 1009-1016.

3. Shah N, Sukumar S. The Hox genes and their roles in oncogenesis. Nat Rev Cancer. 2010; 10: 361-371.

4. Makiyama K, Hamada J-I, Takada M, Murakawa K, Takahashi Y, Tada M, Tamoto E, Shindo G, Matsunaga A, Teramoto K-I, Komuro K, Kondo S, Katoh H, et al. Aberrant expression of HOX genes in human invasive breast carcinoma. Oncol Rep. 2005; 13: 673-679.

5. Hur H, Lee J-Y, Yun HJ, Park BW, Kim MH. Analysis of HOX Gene Expression Patterns in Human Breast Cancer. Mol Biotechnol 2013; 56: 64-71.

6. Hsieh-Li HM, Witte DP, Weinstein M, Branford W, Li H, Small K, Potter SS. Hoxa 11 structure, extensive antisense transcription, and function in male and female fertility. Development 1995; 121: 1373-1385.

7. Fiegl H, Windbichler G, Mueller-Holzner E, Goebel G, Lechner M, Jacobs IJ, Widschwendter M. HOXA11DNA methylation-A novel prognostic biomarker in ovarian cancer. Int J Cancer 2008; 123: 725-729.

8. Hwang J-A, Lee BB, Kim Y, Park S-E, Heo K, Hong S-H, Kim Y-H, Han J, Shim YM, Lee Y-S, Kim D-H. HOXA11 hypermethylation is associated with progression of nonsmall cell lung cancer. Oncotarget 2013; 4: 2317-2325. doi: 10.18632/oncotarget.1464.

9. Bai Y, Fang N, Gu T, Kang Y, Wu J, Yang D, Zhang H, Suo Z, Ji S. HOXA11 gene is hypermethylation and aberrant expression in gastric cancer. Cancer Cell Int 2014; 14: 79.

10. Novak P, Jensen T, Oshiro MM, Wozniak RJ, Nouzova M, Watts GS, Klimecki WT, Kim C, Futscher BW. Epigenetic inactivation of the HOXA gene cluster in breast cancer. Cancer Res 2006; 66: 10664-10670.

11. Avraham A, Sandbank J, Yarom N, Shalom A, Karni T, Pappo I, Sella A, Fich A, Walfisch S, Gheber L, Evron E. A similar cell-specific pattern of HOXA methylation in normal and in cancer tissues. Epigenetics 2014; 5: 41-46.

12. Skiriutė D, Vaitkienė $P$, Ašmonienè V, Steponaitis $G$, Deltuva VP, Tamašauskas A. Promoter methylation of 
AREG, HOXA11, hMLH1, NDRG2, NPTX2 and Tes genes in glioblastoma. J Neurooncol 2013; 113: 441-449.

13. Connell KA, Guess MK, Chen H, Andikyan V, Bercik R, Taylor HS. HOXA11 is critical for development and maintenance of uterosacral ligaments and deficient in pelvic prolapse. J Clin Invest 2008; 118: 1050-1055.

14. Taylor HS, Igarashi P, Olive DL, Arici A. Sex steroids mediate HOXA11 expression in the human periimplantation endometrium. J Clin Endocrinol Metab 1999; 84: 1129-1135.

15. Chau YM, Pando S, Taylor HS. HOXA11 silencing and endogenous HOXA11 antisense ribonucleic acid in the uterine endometrium. J Clin Endocrinol Metab 2002; 87: 2674-2680.

16. Rønneberg JA, Fleischer T, Solvang HK, Nordgard SH, Edvardsen H, Potapenko I, Nebdal D, Daviaud C, Gut I, Bukholm I, Naume B, Børresen-Dale A-L, Tost J, et al. Methylation profiling with a panel of cancer related genes: association with estrogen receptor, TP53 mutation status and expression subtypes in sporadic breast cancer. Mol Oncol 2011; 5: 61-76.

17. Kamalakaran S, Varadan V, Giercksky Russnes HE, Levy D, Kendall J, Janevski A, Riggs M, Banerjee N, Synnestvedt M, Schlichting E, Karesen R, Shama Prasada K, Rotti H, et al. DNA methylation patterns in luminal breast cancers differ from non-luminal subtypes and can identify relapse risk independent of other clinical variables. Mol Oncol 2011; 5: 77-92.

18. Conway K, Edmiston SN, May R, Kuan PF, Chu H, Bryant C, Tse C-K, Swift-Scanlan T, Geradts J, Troester MA, Millikan RC. DNA methylation profiling in the Carolina Breast Cancer Study defines cancer subclasses differing in clinicopathologic characteristics and survival. Breast Cancer Res 2014; 16: 450.

19. Dulaimi E, Hillinck J, Ibanez de Caceres I, Al-Saleem T, Cairns P. Tumor suppressor gene promoter hypermethylation in serum of breast cancer patients. Clin Cancer Res 2004; 10: 6189-6193.

20. Bird AP. DNA methylation patterns and epigenetic memory. Genes Dev 2002; 16: 6-21.

21. Whitcomb BP, Mutch DG, Herzog TJ, Rader JS, Gibb RK, Goodfellow PJ. Frequent HOXA11 and THBS2 promoter methylation, and a methylator phenotype in endometrial adenocarcinoma. Clin Cancer Res 2003; 9: 2277-2287.

22. Cui Y, Gao D, Linghu E, Zhan Q, Chen R, Brock MV, Herman JG, Guo M. Epigenetic changes and functional study of HOXA11 in human gastric cancer. Epigenomics 20157: 201-213.

23. Yemelyanova A, Vang R, Kshirsagar M, Lu D, Marks MA, Shih IM, Kurman RJ. Immunohistochemical staining patterns of p53 can serve as a surrogate marker for TP53 mutations in ovarian carcinoma: an immunohistochemical and nucleotide sequencing analysis. Mod Pathol 2011; 24: 1248-1253.
24. Mirza S, Sharma G, Pandya P, Ralhan R. Demethylating agent 5-aza-2-deoxycytidine enhances susceptibility of breast cancer cells to anticancer agents. Mol Cell Biochem 2010; 342: 101-109.

25. Jeon MJ, Kim EJ, Lee M, Kim H, Choi JR, Chae HD, Moon YJ, Kim SK, Bai SW. MicroRNA-30d and microRNA-181a regulate HOXA11 expression in the uterosacral ligaments and are overexpressed in pelvic organ prolapse. J Cell Mol Med 2015; 19: 501-509.

26. Holland DG, Burleigh A, Git A, Goldgraben MA, PerezMancera PA, Chin S-F, Hurtado A, Bruna A, Ali HR, Greenwood W, Dunning MJ, Samarajiwa S, Menon S, et al. ZNF703 is a common Luminal B breast cancer oncogene that differentially regulates luminal and basal progenitors in human mammary epithelium. EMBO Mol Med 2011; 3: 167-180.

27. Davidson NE, Sukumar S. Of Snail, mice, and women. Cancer Cell 2005; 8: 173-174.

28. Hammond MEH, Hayes DF, Dowsett M, Allred DC, Hagerty KL, Badve S, Fitzgibbons PL, Francis G, Goldstein NS, Hayes M, Hicks DG, Lester S, Love R, et al. American Society of Clinical Oncology/College Of American Pathologists guideline recommendations for immunohistochemical testing of estrogen and progesterone receptors in breast cancer. J Clin Oncol 2010; 28: 2784-2795.

29. Wolff AC, Hammond MEH, Schwartz JN, Hagerty KL, Allred DC, Cote RJ, Dowsett M, Fitzgibbons PL, Hanna WM, Langer A, McShane LM, Paik S, Pegram MD, et al. American Society of Clinical Oncology/College of American Pathologists guideline recommendations for human epidermal growth factor receptor 2 testing in breast cancer. J Clin Oncol 2007; 25: 118-145.

30. Cheang MCU, Chia SK, Voduc D, Gao D, Leung S, Snider J, Watson M, Davies S, Bernard PS, Parker JS, Perou CM, Ellis MJ, Nielsen TO. Ki67 index, HER2 status, and prognosis of patients with luminal B breast cancer. J Natl Cancer Inst 2009; 101: 736-750.

31. Jung S-Y, Kim HY, Nam B-H, Min SY, Lee SJ, Park C, Kwon Y, Kim E-A, Ko KL, Shin KH, Lee KS, Park IH, Lee $\mathrm{S}$, et al. Worse prognosis of metaplastic breast cancer patients than other patients with triple-negative breast cancer. Breast Cancer Res Treat 2010; 120: 627-637.

32. Goldhirsch A, Wood WC, Coates AS, Gelber RD, Thürlimann B, Senn H-JPanel members. Strategies for subtypes--dealing with the diversity of breast cancer: highlights of the St. Gallen International Expert Consensus on the Primary Therapy of Early Breast Cancer 2011. 2011; pp 1736-1747.

33. Eads CA, Danenberg KD, Kawakami K, Saltz LB, Blake C, Shibata D, Danenberg PV, Laird PW. MethyLight: a highthroughput assay to measure DNA methylation. Nucleic Acids Res. 2000; 28: E32.

34. Livak KJ, Schmittgen TD. Analysis of Relative Gene Expression Data Using Real-Time Quantitative PCR and the 2- $\Delta \Delta$ CT Method. Methods 2001; 25: 402-408. 
35. Sakata M, Kitamura Y-H, Sakuraba K, Goto T, Mizukami H, Saito M, Ishibashi K, Kigawa G, Nemoto H, Sanada Y, Hibi K. Methylation of HACE1 in gastric carcinoma. Anticancer Res 2009; 29: 2231-2233.

36. Shan M, Yin H, Li J, Li X, Wang D, Su Y, Niu M, Zhong Z, Wang J, Zhang X, Kang W, Pang D. Detection of aberrant methylation of a six-gene panel in serum DNA for diagnosis of breast cancer. Oncotarget, 2016; 14: 18485-94. doi: 10.18632/oncotarget.7608.

37. Herman JG, Graff JR, Myöhänen S, Nelkin BD, Baylin SB. Methylation-specific PCR: a novel PCR assay for methylation status of $\mathrm{CpG}$ islands. Proc Natl Acad Sci USA 1996; 93: 9821-9826.

38. Oshiro MM, Watts GS, Wozniak RJ, Junk DJ, L MunozRodriguez J, Domann FE, Futscher BW. Mutant p53 and aberrant cytosine methylation cooperate to silence gene expression. Oncogene 2003; 22: 3624-3634.

39. Lynch VJ, Brayer K, Gellersen B, Wagner GP. HoxA-11 and FOXO1A Cooperate to Regulate Decidual Prolactin Expression: Towards Inferring the Core Transcriptional Regulators of Decidual Genes. PLoS ONE 2009; 4: e6845-8. 